\title{
Harnessing Entrepreneurial Education in the Technical Universities: A Panacea to Youth Unemployment
}

\author{
Daniel Larbi ${ }^{1}$, Francis Gyedu ${ }^{2}$ \\ ${ }^{1}$ General Service Directorate, Accra Technical University, Accra, Ghana \\ ${ }^{2}$ Examination Office, Accra Technical University, Accra, Ghana
}

Email address:

dlarbi@atu.edu.gh (D. Larbi), fgyedu@atu.edu.gh (F. Gyedu)

${ }^{*}$ Corresponding author

\section{To cite this article:}

Daniel Larbi, Francis Gyedu. Harnessing Entrepreneurial Education in the Technical Universities: A Panacea to Youth Unemployment. Journal of Human Resource Management. Vol. 9, No. 1, 2021, pp. 15-21. doi: 10.11648/j.jhrm.20210901.12

Received: January 5, 2021; Accepted: February 14, 2021; Published: March 22, 2021

\begin{abstract}
Entrepreneurship, in developing countries like Ghana, is vital to development of the country. Ghana has human resource capable of retrieving, processing and utilizing her natural resources for economic development. Yet, Ghana as a developing country is grappling with poverty and unemployment. The educational system and its curricula activities as well as the various associated training programmes in the country, are generally geared towards preparing the youth for white color jobs other than self-employment skills. This paper therefore focuses on entrepreneurial education with the emphasis on equipping the youth with skills and competence needed to enhance their economic status. The methodology used was descriptive and quantitative. The sample population was drawn from graduate students of three Technical Universities (TUs). The paper looked at the integration of entrepreneurial education programmes in the TUs curricula towards addressing job creation. It was found out that, the Ghanaian educational system has not been a force to reckon with when it comes to equipping the students or graduates with the requisite skills and competencies to develop themselves economically and career wise so as to produce graduates who are independent. This paper brings to the fore the fact that, in order to curb the unemployment situation in the country, emphasis should be laid on entrepreneurial education to develop the mind-set of the youth towards employment. Some recommendations were made for the youth to be self-reliant.
\end{abstract}

Keywords: Entrepreneurship, Unemployment, Skills, Curricula, Human Resource, Education

\section{Background}

According to the National Policy on Youth Development, the youth category of the Ghanaian population refers to all citizens of the Republic of Ghana who fall within the age bracket of 18-35years. Over the years, Ghana has seen an upsurge in the rate of the youth population as compared to the other aspects of the population like the young and the aged. In 2015, however, the Ghana Labour Force Survey conducted revealed that, the youth constitute about $35.9 \%$ of the Ghanaian population. The Government of Ghana therefore recognized the fact that, the youth form a veritable and a critical human resource for the country with a vibrant global outlook which could be used for the agenda of national development. Youth empowerment in the area of entrepreneurial knowledge and skills development is therefore very prudent for ensuring economic development and nation building for the Republic of Ghana [6]. This is because, with the current statistics, there are about $16.9 \%$ of the graduate youth who are unemployed. Even giving those employed with a high labour under utilization rate of $42 \%$ with a future estimate of a higher proportional rate of unemployment [15].

In recent times, most of these Universities in Ghana including the Technical Universities (TUs) have initiated a course geared towards entrepreneurship education to their students in order to create some level of awareness that can boost their morale and encourage them to consider selfemployment as a life time career option that must be pursued. For instance, Accra Technical University (ATU) and Takoradi Technical University (TTU), which happen to be among the leading technical universities in Ghana, have taken up this challenge and have introduced entrepreneurial programmes such as 'Business incubator' or 'world of work'. The 
question or issue about what has happened to these levels of developments and initiatives as well as the effects of these entrepreneurship educational initiatives on students' career progressions including their attitudes towards starting a business requires a critical investigation.

Graduate employability is an issue of concern in many areas. This study, however, focuses on graduates of Technical Universities/Polytechnics. For the purpose of this study, graduate unemployment is defined as the number or the proportion of degree/HND holders in the economy who are capable and willing to work, but are unable to find jobs [3].

\subsection{Problem Statement}

Ghanaian education is deprived of certain elements that are very critical in eliminating the increasing levels of unemployment within the country. Developing entrepreneurial skills through education is appropriate since it is an avenue for economic growth and development of a nation. Much emphasis should be made on how to develop the skills of the students with broad emphasis laid on personal growth and development. The prevalence of unemployment in the country has brought about social stratification and segregation among the citizenry. This is because the educational system has failed to empower its graduate with employable skills needed to slot them into the various sectors of the economy. The central evolutions that hover around educational policies in Ghana should be directed at the need to nurturing the youth of Ghana by inculcating into them the knowledge of rudimentary entrepreneurial development, oneness in the heritage of culture as well as the discovery of diverse abilities and capabilities that are related to structures, systems and cultures of others [8]. Some researchers had the view that job seekers in Ghana do not actually have the requisite skills that actually match the job requirements of employers. For example, McGrath argued that, the educational system in Ghana has its liberal bias, this has therefore flooded the labour market with school leavers who do not actually possess the requisite skills that are fitting for the job market [9]. A lot of the graduates that are within the country therefore lack entrepreneurial skills that can facilitate self-employment. Another critical factor is the kind of perceptions of policy makers and the youth themselves about employment. To the policy maker and the youth on intellectual and psychomotor skills, their view of employment is based on the fact that work is being done for someone at a monthly fee or salary. This mindset has therefore been one main impediment that has always hindered the tertiary institutions from providing skills and training [10]. This has therefore established a norm that school leavers are supposed to enter into the formal sector for jobs. Because these jobs are not readily available for the job seekers, there is always therefore a gap between the capabilities of the graduate and the available jobs. Aside from the above, other factors such as poor governance, ineffective targeting of the poor resulting in resource being spread among competing projects, overlapping of functions, poor coordination and lack of sustainable measures are all to be mentioned as source of graduate unemployment in Ghana and the West African sub region [9].

\subsection{Objectives of the Study}

(1) Investigate the influence of entrepreneurship education on career intentions and aspirations of graduate students.

2) Examine the influence of entrepreneurship education on attitude towards business start-ups among graduate students.

\subsection{Research Questions}

1) What is the influence of entrepreneurship education on career intentions and aspirations of graduate students?

2) What is the influence of entrepreneurship education on attitude towards business start-ups among graduate students?

\subsection{The Purpose of the Study}

Entrepreneurship education has become a global menace in recent times among most developing economies in the world. Most studies have concentrated on entrepreneurship education in the developed countries. The specifics and geographical and economic differences present undiluted differentiation among students in both developed and developing countries in relation to entrepreneurship education. A study in a developing country may present a trend that might be unique to global perspective of graduate unemployment across the globe. The study therefore sought to identify how entrepreneurship education affects the career intentions of graduates and how such education contributes to their attitude towards setting up businesses within the economy of Ghana. This study focuses on graduates from the technical universities/polytechnics.

\section{Literature Review}

\subsection{Introduction}

In Ghana, the youth make up about $70 \%$ of the entire population These vibrant ones are mostly challenged with issues of poverty and unemployment. A lot secondary and tertiary education drop outs as well as those who were able to pass through, are mostly challenged with intense competition on the job market simply because they lack the requisite skills [7]. For this reason, these ones linger from dawn to dusk all in search of white color jobs to earn a living. The rationale behind entrepreneurial education in Ghana includes (a) the provision of trained manpower especially in the field of applied sciences, on the field of technology especially regarding craftmanship, advanced craftmanship and technical levels. (b) the provision of technical knowledge and vocational skills necessary for agricultural, commercial and economic development. (c) to provide training and impact the necessary skills to individual who shall be self-reliant economically [1]. 


\subsection{Conceptual Review}

\subsubsection{The Concept of Entrepreneurship Development in the Technical Universities (TUs)}

Entrepreneurship is more than simply "starting a business." It is a process through which individuals from the Technical Universities (TUs) identify opportunities, allocate resources, and create value. This creation of value is often through the identification of unmet needs, or through the identification of opportunities for change. It is the act of being an entrepreneur which is seen as "one who undertakes innovations with finance and business acumen in an effort to transform innovations into economic goods. Hence, entrepreneurs see "problems" as "opportunities," and then take action to identify the solutions to those problems and the customers who will pay to have those problems solved. Entrepreneurial success is simply a function of the ability of the students from these technical universities to see opportunities in the marketplace, initiate change (or take advantage of change) and create value through solutions [2].

\subsubsection{Youth Unemployment in Ghana: A Conceptual Clarification}

Every economy is characterized by both active and inactive populations. The economically active ones are referred to as the population willing and able to work, and include those actively engaged in the production of goods and services and those who are unemployed. The International Labour Organization (ILO) defines the unemployed as numbers of the economically active population who are without work but available for and seeking work, including people who have lost their jobs and those who have voluntarily left work [17]. According to Fajana, unemployment refers to a situation where people who are willing and capable of working are unable to find suitable paid employment. It is one of the macro-economic problems which every responsible government is expected to monitor and regulate. The higher the unemployment rate in an economy the higher would be the poverty level and associated welfare challenges [5].

\subsection{Empirical Review}

Recently, unemployment has hit the Ghanaian youths badly. A situation whereby conglomerate of youths with diverse background, willing and able to work, but cannot find any and some losing their lives is terrible. Given the lack of sufficient employment opportunities in the formal sector, young people may be compelled to engage in casual work and other unorthodox livelihood sources, thus leading to underemployment [4]. There are various forms of unemployment that have been identified. These include seasonal, frictional, cyclical, and structural unemployment. Unemployment is measured among people in the labour force [11]. Unemployment is a global trend, but it occurs mostly in developing countries of the world, with attendant social, economic, political, and psychological consequences. Thus, massive youth unemployment in Ghana as a country is an indication of far more complex problems. However, with the institution of Nation Builder's Corps (NABCO) that has sought to employ one hundred thousand graduates, and Youth Employment Agency (YEA) that has also employed over hundred thousand youths in Ghana the unemployment rate in Ghana was drastically since 2017.

\subsubsection{Entrepreneurship and Economic Development in Ghana}

It is a fact that misplaced objective can lead the unemployed Ghanaian youth to engage themselves in social vices such as hostage taking, kidnapping, pipeline vandalism, and economic sabotage, internet frauds and bombing [12]. The traits of creativity, risk-loving, innovation, strategic thinking and constructive engagement against the government by discontented Ghanaians could as well be directed to entrepreneurship development [1]. Therefore, it is of great importance to know that for a country to achieve a place in the world's economy it must be able to provide opportunities for the unemployed youth to engage in entrepreneurship activities in conductive environmental variables.

\subsubsection{Prospects of Entrepreneurship Development in the TUs and Employment Generation in Ghana}

All the above cited problems notwithstanding, plausibility of entrepreneurship development in the Technical Universities to generate employment abound hence the government fully appreciates the opportunities entrepreneurship creates for employment generation, their contributions to economic growth and development as well as the constraints and difficulties in their operating environment. These explain why in the past years or so, governments have established various support institutions and relief measures specially structured to render assistance and succor to minimize the constraints, which entrepreneurship typically faces in these Technical Universities if not to eliminate them [1]. The support institutions established by the government range from specialized banks designed to focus on the funding of Small and Medium Enterprises to agencies and departments all meant to give a flip to the fortunes of Small and Medium Enterprises. It is also pertinent to note that government policies behind the establishment and operations of the Small and Medium Enterprise support institutions had not been effective and productive. From all indications of observed lapses inherent in them, the policies were either defective in their formulation and conceptualization, or were not truly and religiously implemented. The comfort is that the governments (local, state and federal) are neither relenting nor giving up in their bid to revamp and invigorate the fortunes of SMEs as to enable them play the expected role in Ghana's economic growth and development [12].

\subsection{Conclusion of Literature Review}

It appears when the Ghanaian youths are ill equipped with entrepreneurial education or skills in the Technical 
Universities; they tend to make little or no change in the economic development of their country. The youths are the leaders of tomorrow. The rate of youth unemployment in Ghana is alarming despite the government's efforts in employing the majority of the youth into the various sectors of the economy through certain interventions and policies. What will happen to the "Transformation Agenda" for Ghana and Sub-Saharan Africa spoken of by most presidents in the sub-Sahara Africa? It is instructive to note that the unemployment has been security challenges, poverty, wars, and lots of social vices. Considering the fact that about $70 \%$ of the entire Ghanaian population are youths, $71 \%$ of which are unemployed graduates, this affected the workforce utility of the country adversely. It is also a pity that these youths and graduate who are qualified, willing and able to work cannot find a job and as such earn nothing. Therefore, the purpose of this study is to create awareness on the need to emphasize entrepreneurship education to help our students to get the needed skills to be either absorbed into the government sector or to establish their organization.

\section{Research Design}

The study employed descriptive research design. As the name implies, descriptive research design seeks to collect data and present the information as it is. It describes the data collected without necessarily doing anything about it. Entrepreneurship education has direct bearing on the intentions and aspirations of the people in building their capacities for self-employment. The descriptive research design was used because it was the best design that was capable of providing answers to the research question. The study again employed the quantitative methodology in the collection and analysis of the data collected. Qualitative methodology goes hand in hand with descriptive research design and it is able to sample opinions from many people. The problem of unemployment in Ghana is endemic and has various aspects. The qualitative methodology, with its use of questionnaire provided the opportunity to sample the views of many unemployed youth across the university.

\subsection{Population and Sampling of the Study}

The target population for this study was graduate students from Accra Technical University. Purposive sampling techniques were used to sample out a total number of 100 to constitute the study sample.

\subsection{Data Collection Instruments}

The instrument used for this research was questionnaire, which was developed by the researchers to gather ample information. The questionnaire gave the respondents the opportunity to objectively respond to the question without any fear of intimidation or political identification. It also enabled the researchers to gather wide range of questions in order to deal adequately with the questionnaire. The only problem was that respondents could not get the opportunity to ask questions for clarification. With this in mind, the researchers ensured that the questions posed were clear to the understanding of their level as HND students. The questions were made up of five personal or bio data as well as five open and closed questions under each research objective.

\subsection{Data Analysis and Presentation}

Data for this study was analyzed by presenting the data collected from the sample of the students from Accra Technical University on statistical tables which made it easy for analysis to be conducted thereafter.

\section{Data Analysis and Presentation}

Table 1. The Influence of Entrepreneurship Education on Career Intentions.

\begin{tabular}{lll}
\hline & Frequency & Percent \\
\hline Further Studies & 21 & 24.14 \\
Employment & 9 & 10.34 \\
Self-Employment & 57 & 65.52 \\
Total & 87 & 100 \\
\hline
\end{tabular}

Source: Field Data, 2020

Table 1 presents the outcome from the perspective of the respondents based on their carrier intentions, which is after the first two years of graduation. In view of this, most of the respondents $10.34 \%(n=9)$ do not want to work under other employers. Again, it became evidential that $65.52 \%(n=57)$ of the respondents aspire to work for others following the exposure to entrepreneurship. However, pursuing a selfemployment carrier that could lead to the employment of others has been the wish of both groups of respondents. The relevance of this in relation to students' exposure to entrepreneurship and career intentions is that, there is a significant relationship to exposure to entrepreneurship education and career intentions.

Table 2. Immediate Career Intentions after Graduation.

\begin{tabular}{lll}
\hline & Frequency & Percent \\
\hline Immediate Career Intention & 11 & 12.64 \\
Further Studies & 8 & 9.2 \\
Employment & 7 & 8.05 \\
Self-Employment & 61 & 70.11 \\
Total & 87 & 100 \\
\hline
\end{tabular}

Source: Field Data, 2020

The level of importance attached to entrepreneurship education as well as its associated career intentions of the student respondents is so enormous and not surprising at all. The programme outline for entrepreneurship is geared towards providing an in-depth scrutiny into the role that small business owners or entrepreneurs play within the economy, including the urge to implement the core skills that are actually required by entrepreneurs, such as creative problem-solving, diagnostic skills, communication and project management. Again, this serves as an avenue for the development of educational initiatives such as the development of business, proposals as well as business 
consultancy that paves the way for the students to integrate accounting, finance, marketing and other business disciplines. It looks like the entrepreneurship programmes both aided in engendering entrepreneurial career intentions and aspirations and encouraged one-in-four $(70.11 \%$ or $n=61)$ of the respondents to include self-employment in the career intention compared to $8.0 \%$ $(\mathrm{n}=7)$ prior to exposure to entrepreneurship. The results outline Table 2. Indicate the extent of the perceived influence of the entrepreneurship education programmes on the career intentions of the respondents.

Table 3. Influence of Entrepreneurship Programme on Career Intentions.

\begin{tabular}{lll}
\hline & Frequency & Percent \\
\hline Not at all & 3 & 3.45 \\
Very little extent & 5 & 5.75 \\
Average Extent & 6 & 6.9 \\
Great Extent & 41 & 47.12 \\
Very Great Extent & 32 & 36.78 \\
Total & 87 & 100.00 \\
\hline
\end{tabular}

Source: Field Data, 2020

Most of the people whose opinion was sought $67.8 \%(n=210)$ agreed to the fact that programs geared towards entrepreneurship have a massive impact on their carrier intentions. This is represented by a weighted average score of 3.9 on a five-point scale, with one representing no influence at all and five for a very great extent of influence, confirming the respondents' perception. Also, the vital relationship that exists between programs of entrepreneurship education and its associated career intentions is worth noting. The impact is that entrepreneurship education positively has an impact on the career intentions of the respondents. This evidently backs the previous studies [16] that found that an entrepreneurship education programme influences students' career intentions. This, therefore, implies that a very remarkable relationship exists between entrepreneurship education programs of respondents as well as their career intentions. The finding from the respondents is quite impressive to note for reasons outlined below. The very first reason is that, the responses show a level of confidence in the entrepreneurial education that is carried out in the tertiary institutions which is indicated by the high ratings of approval. Again, it shows the level of match between the educational curricula and the entrepreneurship programs offered. These findings contradict a similar study of three decades ago that found that higher education inhibited entrepreneurship [7]. Secondly, the study brought to the fore the fact that the universities play a very significant role with a big influence on developing society through the numerous programs they offer.

Table 4. Perceived Barriers to Business Start-ups.

\begin{tabular}{lll}
\hline & Frequency & Percent \\
\hline Finance & 39 & 44.83 \\
Business Ideas & 11 & 12.64 \\
How to Explore Business Opportunities & 21 & 24.14 \\
Business Management Skills & 8 & 9.20 \\
Business Advice & 8 & 9.20 \\
& 87 & 100.00 \\
\hline
\end{tabular}

Source: Field Data, 2020
The respondents were once again asked to give their opinion on the barriers to business starts-ups of which the responses are presented in Table 4. About 33\% of the respondents, $(44.83 \%$ or $\mathrm{n}=39)$ indicated financial constraints as a major barrier to business start-ups in Ghana. With 8 of the respondents $(9.20 \%)$ also indicating that the lack of business advisory services also serves as a major hindrance when it comes to achieving the objectives of selfemployment. Aside that, more than one quarter $(24 \%$ or $n=21)$ of the respondents were of the opinion that the lack of technical know-how to explore business opportunities also poses a major challenge to business start-ups. Nevertheless, some $12.64 \%(n=11)$ of the respondents also attested to the fact that the absence of business ideas also serves as a major barrier to business set-ups. Another revelation is that only $9.20 \%(n=8)$ of the respondents perceived lack of business and management skills as a barrier. The three major barriers perceived by student respondents were finance, lack of business ideas and how to exploit business opportunities. This finding appears to support earlier studies by reference [11] where finance and lack of business experience were reported as key barriers to business start-ups.

Table 5. Entrepreneurship Education Enabled Students to Learn Some Vocational Skills.

\begin{tabular}{llll}
\hline & & Frequency & Percent \\
\hline \multirow{4}{*}{ Valid } & Strongly Agree & 38 & 43.7 \\
& Agree & 26 & 29.9 \\
& Not Sure & 15 & 17.2 \\
& Disagree & 1 & 1.1 \\
& Strongly Disagree & 7 & 8.0 \\
& Total & 87 & 100 \\
\hline
\end{tabular}

Source: Field Data, 2020

The respondents were asked to indicate by choosing from the list of responses how entrepreneurship education offered in the university has enabled them to learn some vocational skills. From the data gathered and represented in the table above, it was evidenced that $43.7 \%$ of the total respondents strongly agreed to this, and this was supported by $29.9 \%$ who agreed. Also, 17.2\% were uncertain with their responses and only $1.1 \%$ and $8 \%$ disagreed and strongly disagreed respectively.

Table 6. The Programmes has Made me Self-reliant and Independent.

\begin{tabular}{llll}
\hline & Frequency & Percent \\
\hline \multirow{4}{*}{ Valid } & Strongly Agree & 12 & 13.8 \\
& Agree & 45 & 51.7 \\
& Not Sure & 10 & 11.5 \\
& Disagree & 6 & 6.9 \\
& Strongly Disagree & 14 & 16.1 \\
& Total & 87 & 100.0 \\
\hline
\end{tabular}

Source: Field Data, 2020

Table 5 above shows the responses gathered on how the students have become self-reliant and independent based on the entrepreneurship programme. Very few of the respondents give a negative response to this question. Most of them gave a positive response. $13.8 \%$ strongly agreed and 
$51.7 \%$ also agreed that, taking up the entrepreneurship programme has given them a sense of being self-reliant.

\section{Research Findings}

Entrepreneurship education is an educational programme introduced to develop the mind-set of the youth towards employment generation, poverty reduction and economic development. The Ghanaian educational system has failed to achieve its goal of equipping individuals with skills and competencies needed to develop economically and have selfreliant citizens. To this end, the country is faced with crises of graduate unemployment and societal poverty due to lack of appropriate skills and competencies required for gainful employment and economic development. Entrepreneurship education is introduced to bring new ideas to life through innovation, creativity and desire to build businesses of lasting value to individuals so as to be self-reliant and useful members of the society. The dream for entrepreneurship education can only be a reality where conscious effort is being made for its full implementation.

It was found that intellectual skills promote the acquisition of comprehensive knowledge of the business and enhances understanding of the concept and theories in entrepreneurship education i.e. risk, assets, liabilities, strength, weakness, opportunity and threat, and accurate records. It also provides the basis for and knowledge of investment in youth; it promotes the preparation of feasibility reports. It enables youths learn how to keep proper and accurate records. The degree of agreement amongst graduates on the influence of intellectual skill for youth employment among the university respondents sampled showed how they need fundamental intellectual skills for operational efficiency and maximization of profit in their self-employment efforts. The findings are in agreement with Agbeze $\mathrm{C}$ who posited that, acquisition of entrepreneurship skills by students would enhance their business acumen and thereby make them have a comprehensive knowledge of business [1]. Nabaho et al posited that for youth to be self-employed, they should acquire basic skills through entrepreneurship education. They emphasized that the possession of these skills will consolidate and enhance their businesses as well as eliminate early failure [14]. From the data collated and analyzed, it was found that, psychomotor skills have the ability to focus on tasks to be accomplished, manipulative skills have ability to produce and accomplish task in their business and ability to determine new ways of manipulating things. This finding corroborated with that of Karue \& Eyovwunu who opined that, training through psychomotor is one of the recognized efforts to move in the paradigm shift to entrepreneurial development in Ghana and should involve bringing together the government and the NBSSI to introduce entrepreneurship education into the curriculum of all tertiary institutions in the country [13].

It is evident from the study that entrepreneurship education exposed to the HND students is creating entrepreneurship awareness and encouraging students to include self- employment in their career intentions and aspirations' options including the integration of positive attitude towards starting their own business. Nevertheless, for these school leavers or graduates to succeed on the job market there are a lot of barriers that should be addressed. They include their inability to translate the successful transfer of the high career aspirations and overwhelming positive attitude towards business start-up need to be addressed. It is against the three perceived barriers to business establishment, namely finance, business and exploitation of business ideas. The reported perceived barriers to business start-ups could possibly explain low business start-up decisions in spite of the high career intentions and aspirations. This observation supports Ghana Statistical Agency report that 'when respondents were asked their most likely career choice considering their actual situation and constraints upon their options, only 5\% indicated that they would probably choose to operate their own businesses [7]. Lack of effective collaboration between stakeholders creates a wide gap between content of course studied and demands of the job market.

There are indications that young graduates are passionate about starting their own business. However, it is certain that few of such ones mostly start their business in accordance with others expressing an interest in them for that matter their level of failure may exceed those in the older group of the population. Entrepreneurship education is so important that there is urgent need for higher educational institutions in Ghana to comply with the Ghana Accreditation Board's directives that entrepreneurship be made compulsory for all students of higher education institutions in Ghana, irrespective of their areas of specialization. This policy decision was based on government awareness of the crucial role of entrepreneurship education and training in fostering employment generation among the teeming youths, economic growth and wealth creation. Entrepreneurship education should as much as possible be inculcated into all spheres of higher learning in Ghana and must be made compulsory for all students in Ghana so as to prepare the minds of these young ones towards employment generation, poverty reduction and economic development.

Mismatch in the training of students and job requirement: Employers mostly blame the universities for this mismatch and accused them of being the main cause of graduate unemployment in the labour market. Most of the skills that emerged out of the study of the industry include practical oriented and problem-solving skills, creative, entrepreneurial, and sound computer knowledge. What was the level of emphasis placed on skill training as compared to the traditional cognitive training? Some of the lecturers of these tertiary institutions also believed strongly that giving a sound cognitive training to students could make them versatile and fit into almost any employment situations. This argument must be labeled against the fact that current developments require in addition to the strong cognitive training, the individual must try and specialize his or her skills that will enable him or her perform better when on the job. Education at a higher level as the tertiary if not able to lead into 
employment then has indeed been a failure looking at all the huge investments that goes into it. The appropriate way forward is indeed to iron out the issues so as to put in place measures that could effectively shape the calibre of graduates produced from the various universities.

The Universities in their quest to offer continuous improvement programs by way of offering to the job market the best quality graduates continue to make claims in their favor even though these claims are not factual. An investment into factual data by the universities as well the organizations continue to be an issue of great importance. The Universities must give attention to investment towards obtaining systematic data regarding their skills demand as well as onwards for the graduates emerging from the various fields so as to be informed better of the skill requirements and curriculum adjustments needed to meet these labour market demands.

A recommendation has been made of the fact that a centre known as Student Enterprise Centre should be established so as to provide business advice, mentorship and other practical support towards the realization of the self-employment aspirations of students. Also, this centre can serve as a link to these graduates to financial institutions such as Ghana Angel Investors Network, the National Board for Small Scale Industries and EMPRETEC- the Spanish acronym for emprendedores (entrepreneurs) and tecnología (technology) to help address the barriers students indicated.

Awareness must be created among the employing organization on the need to frequently liaise with these tertiary institutions more often most importantly regarding issues of curriculum review and labor market projections so as to enhance the availability of timely information concerning the career pathways. There are some employers who do not mostly participate regularly in institutional curriculum reviews; aside that they also fail to provide adequate opportunities for students to undertake volunteering and internships before they graduate.

\section{References}

[1] Agbeze C. (2012) Entrepreneurship: The need to create wealth.... Why not now. Ohafia Today. 2 (32): 7-12.

[2] Binks M, and Vale. P. (1990) Entrepreneurship and Economic Change. London: McGraw Hill.

[3] Dabalen, A., B. Oni, \& O. Adekoka, (2000). Labour Market Prospects for University Graduates in Nigerian Higher Education Management, 14: 1-36 for Tertiary Graduates in
Ghana. A World Bank /National Council for Tertiary Education and the National Accreditation Board Project Report. Accra Ghana.

[4] Echebiri, R. N. (2005). Characteristics and Determinants of Urban Youth Unemployment in Umuahia, Nigeria: Implications for Rural Development and Alternative Labor Market Variables. A Paper presented at the ISSER/Cornell/World Bank conference on "Shared Growth in Africa" held in Accra, Ghana, July 21-22.

[5] Fajana (2000). Functioning of the Nigerian Labour Market, Labonfin and Company, Lagos.

[6] Ghana Labour Force Survey, 2015.

[7] Ghana Statistical Agency, 2010.

[8] Karabchuk, T., \& Zabirova, A. (2018). Informal employment in service industries: estimations from nationally representative Labour Force Survey data of Russian Federation. The Service Industries Journal, 38 (11-12), 742-771.

[9] McGrath, (1999). Learning to Compete: Education, Training and Enterprise in Ghana, Kenya and South Africa, DFID, UK, 2 .

[10] National Bureau of Statistics. (2014). Statistical News: Labor Force Statistics No. 476. Abuja: The NBS Obadan M. I, Odusola A. Y (2001). Productivity and Unemployment in Nigeria. Ibadan: NCEMA.

[11] Osei B et al (1993). Impact of Structural Adjustment on Small Scale Enterprises in Ghana. In A. H. J. Helsing and T. Kolstee (Eds.), Small Enterprises and Changing Policies, Structural Adjustment, Financial Policy and Assistance Programs in Africa. London: ITR Publications.

[12] Oyelola, O. T., N. C. Igwe, I. O. Ajiboshin, and S. B. Peluola. "Entrepreneurship education: Solution to youth unemployment in Nigeria." Journal of Poverty, Investment and Development 5, no. 2014 (2014): 149-157.

[13] Karue, O. O., \& Eyovwunu, D. (2014). Entrepreneurial Education and Small Scale Business Development among Students of College of Education, Warri, Delta State. Merit Research Journal of Education and Review, 2, 185-193.

[14] Nabaho, Lazarus, Jessica Norah Aguti, and Joseph Oonyu. "Making sense of an elusive concept: Academics' perspectives of quality in higher education." Higher Learning Research Communications 7.2 (2017): 2.

[15] Owusu-Ansah, W., \& Poku, K. (2012). Entrepreneurship Education, a Panacea to Graduate Unemployment in Ghana? International Journal of Humanities and Social Sciences, 2 (15), 211-215.

[16] International Labour Organization (ILO) ISBN 978-92-2127591-6. 